\title{
Development of an Intelligent Safety System in Automobile
}

\author{
Mr. Chandrashekhar Padole ${ }^{1}$, Mr. Mahesh Kanojiya ${ }^{2}$, Aniket Shende ${ }^{3}$, Amit Kurzekar ${ }^{4}$, Aditya \\ Gohate $^{5}$, Saurabh Dhote ${ }^{6}$ \\ ${ }^{12}$ Assistant Professor, UG Students ${ }^{3456}$ \\ Department of Mechanical Engineering, Nagpur Institute of Technology, Nagpur, India
}

DOI: 10.46335/IJIES.2020.5.7.7

\begin{abstract}
In this project the innovative idea of implementing intelligent safety system using pneumatic bumper is presented using prototype model and thereby analyzed its various parameters for regular and daily realistic applications. Intelligent safety system using pneumatic bumper is one of the smart options which can be implemented in various applications for protecting the passenger without any jerky motion or without any harm. In the project our main thing is to protect the passenger from the jerky motion after the obstacles suddenly comes in front of our vehicle. Here infrared sensor plays a vital role in determining intelligent safety system generated by sensing the obstacles and activation of pneumatic bumper within a second. Design of intelligent safety depends upon the effectiveness of infrared sensor and pneumatic bumper. Design parameters are calculated and actual and theoretical values are compared.
\end{abstract}

Keywords- Automobile, road safety, intelligent system, design.

\section{I- INTRODUCTION}

A

bout 1.35 million people die each year on the world's road as per the report given by World Health Organization. 54\% of those dying on the world's roads are vulnerable road users. 22 countries have amended their laws to bring them into line with best practice on one or more key risk factors for road traffic injuries between over the past 3 years. In New Delhi, the capital of India, the frequency of traffic collisions is 40 times higher than the rate in London, the capital of the United Kingdom. In 2015, one person dies every 4 minutes in roads collisions in India, according to NGO 'Indians for Road Safety'. It is necessary to minimize the road accidents. Every $1 \%$ increase in mean speed produces a $4 \%$ increase in the fatal crash risk and a $3 \%$ increase. In the serious crash risk the death risk for pedestrians hit by car fronts rises rapidly (4.5 times from $50 \mathrm{~km} / \mathrm{h}$ to 65 $\mathrm{km} / \mathrm{h}$ ). The fatality risk for car occupants is $85 \%$ at 65 $\mathrm{km} / \mathrm{h}$ in car-to-car side impacts. Road traffic injuries can be prevented by involvement from multiple sectors such as transport, police, health, education, and actions that address the safety of roads, vehicles, and road users. Effective measures include designing safer infrastructure and incorporating road safety features into land-use and transport planning, improving the safety features of vehicles, improving post-crash care for victims of road crashes, setting and enforcing laws relating to key risks, and raising public awareness. This paper presents a new system that can solve problem of vehicle crashing where vehicle will stop automatically due to obstacle thus minimizing the chances of collision. An intelligent safety system is proposed by incorporating bumper operated by pneumatic system assisted by electronic sensor.

\section{II- METHOLOGY}

Factors considered in designing the system are:-

1. Braking distance

2. Distance of obstacle in front

3. Speed of vehicle 


\section{$w w w . i j i e s . n e t$}

Braking Distance: - It is the distance between the point of application of brakes and the point at which the vehicle comes to complete stop from the present speed. Distance of obstacle in front:-The distance of any obstacle, a parked or a moving vehicle or a road block is sensed using an infrared sensor and it is fed to relay.

Speed of vehicle:-The braking distance of the vehicle depends to a large extent on the speed of the vehicle. Here aim is to develop the prototype model such that it will reduce the chances of collision with obstacle and thus ensure the safety of individual. A CAD model is developed considering parameters such that

1. Type of vehicle

2. Width of vehicle

3. Velocity of vehicle coming from opposite direction

4. Impact load

5. Length of guard

6. Cross section of guard member

System will be implemented by use of pneumatic cylinder and infrared sensor for the working of system. The proposed prototype 3D model is as follows:

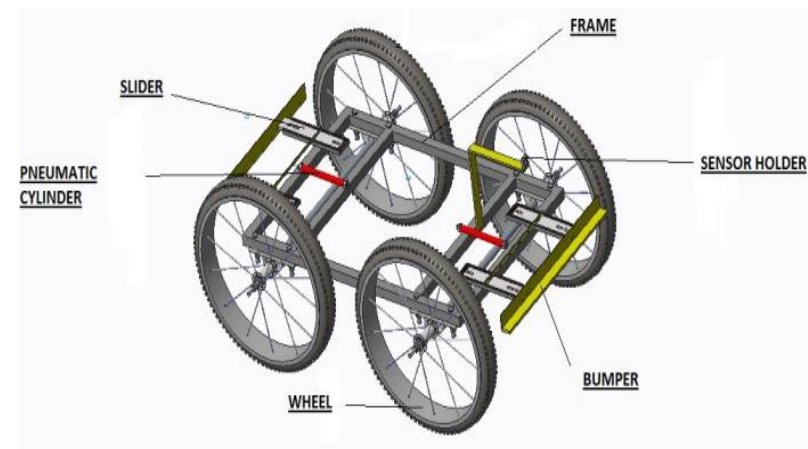

Fig. 1 Prototype 3D model

System will be implemented by use of pneumatic cylinder and infrared sensor for the working of system. The proposed prototype 3D model is as follows:

\section{III- DESIGN \& CALCULATION}

\section{A) Design calculation for Pneumatic Cylinder}

In the field of pneumatics, pressure specifications usually refer to a reference pressure, i.e. the atmospheric pressure. The atmospheric pressure depends on the weather and varies on sea-level between approx. 0.980 bar and at approx. 1.040 bar. In order to be able to do calculations containing the quantity atmospheric pressure, a quantity called standard pressure has been fixed:
Atmospheric standard pressure $($ DIN 1343) $=1.01325$ bar. The SI unit (international system of units) of pressure $\mathrm{P}$ is the Pascal $(\mathrm{Pa})$.

$$
1 \mathrm{~Pa}=1 \mathrm{~N} / \mathrm{m}^{2}
$$

A further authorized unit is Bar (bar).

$$
1 \text { bar }=100.000 \mathrm{~Pa}=105 \mathrm{~Pa}
$$

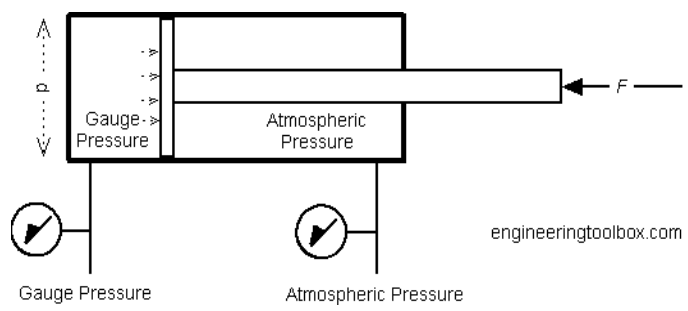

Fig 2: Single Acting Cylinder

The force exerted by a single acting pneumatic cylinder can be expressed as

$$
\begin{aligned}
& \mathrm{F}=\mathrm{pA} \\
& =\mathrm{p} \pi \mathrm{d}^{2} / 4 \\
& \text { where } \\
& \qquad \begin{aligned}
\mathrm{F} & =\text { force exerted }(\mathrm{N}) \\
\mathrm{p} & =\text { gauge pressure }\left(\mathrm{N} / \mathrm{m}^{2}, \mathrm{~Pa}\right) \\
\mathrm{A} & =\text { full bore area }\left(\mathrm{m}^{2}\right) \\
\mathrm{d} & =\text { full bore piston diameter }(\mathrm{m})
\end{aligned}
\end{aligned}
$$

\section{B) Calculations for finding force of attacking four wheeler}

(Assuming $100 \mathrm{~km} / \mathrm{hr}$ Speed)

Velocity of the four wheeler is $27.77 \mathrm{~m} / \mathrm{s}$

Acceleration is $7.71 \mathrm{~m} / \mathrm{s}^{2}$

So, mass of driver is $80 \mathrm{~kg}$

We have,

$$
\begin{aligned}
\text { Force } & =\text { Mass } \times \text { Acceleration } \\
& =80 \times 7.71 \\
\text { Force } & =616 \mathrm{~N} \\
\text { Force } & =616 \times 10^{-3} \\
\text { Force } & =0.6 \mathrm{KN}
\end{aligned}
$$

So, at the force of $0.6 \mathrm{KN}$ the attacking four wheeler crash on our vehicle.

\section{C) Calculations for our model}

$\mathrm{P}=2 \times \pi \times \mathrm{N} \times \mathrm{T} / 60$

$\mathrm{P}=2 \times 3.14 \times 3000 \times 0.196 / 60$

Power $=19.6 \mathrm{~W}$

Now,

Power=Force $\times$ velocity

$$
19.6=\text { Force } \times 27.77
$$

Therefore,

Force $=27.77 / 19.6$

Force $=1.41 \mathrm{KN}$

So, our model can sustain more force as compared to attacking four wheeler force.

D) Shear Force and Bending Moment Calculation 


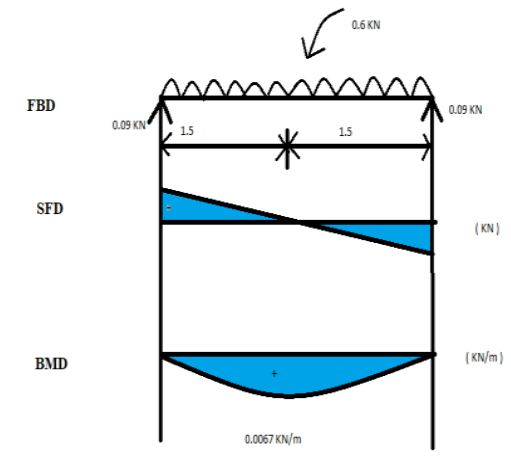

Fig 3: FBD, SFD \& BMD

a) Shear Force Calculation

$\Sigma \mathrm{M}_{\mathrm{A}}=0$

$-\mathrm{RB}_{\mathrm{y}} \times 0.3+(0.6 \times 0.3) \times 0.3 / 2=0$

$-\mathrm{RB}_{\mathrm{y}} \times 0.3+(0.18) \times 0.15=0$

$-\mathrm{RB}_{\mathrm{y}} \times 0.3+0.027=0$

$\mathrm{RB}_{\mathrm{y}}=0.09 \mathrm{KN}$

$\Sigma \mathrm{F}_{\mathrm{y}}=0$,

$\mathrm{RA}_{\mathrm{y}}+\mathrm{RB}_{\mathrm{y}}=0.6 \times 0.3$

$\mathrm{RA}_{\mathrm{y}}=0.18-0.09$

$\mathrm{RA}_{\mathrm{y}}=0.09 \mathrm{KN}$

b) Bending Moment Calculations

$$
\begin{aligned}
\operatorname{Mmax} & =\mathrm{WL}^{2} / 8 \\
& =0.6 \times(0.3)^{2} / 8 \\
& =0.0067 \mathrm{KN} / \mathrm{m}
\end{aligned}
$$

First find out the $\mathrm{Y}$ with respect to the base $\mathrm{AB}$

$\mathrm{A}_{1}=75 \mathrm{~mm}^{2}$

$\mathrm{A}_{2}=66 \mathrm{~mm}^{2}$

$\mathrm{y}_{1}=1.5 \mathrm{~mm}$

$\mathrm{y}_{2}=14 \mathrm{~mm}$

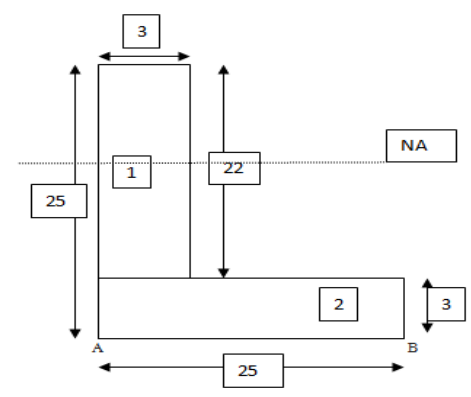

Fig 4: Section of Beam

Therfore $\mathrm{Y}=\mathrm{A}_{1} \mathrm{Y}_{1}+\mathrm{A}_{2} \mathrm{Y}_{2} /\left(\mathrm{A}_{1}+\mathrm{A}_{2}\right)$

$$
=7.351 \mathrm{~mm}
$$

Now find out the Moment of Inertia about Neutral Axis $\mathrm{I}_{\mathrm{m}}=\left[\left(\mathrm{bd}^{3}\right) / 12+\mathrm{A}_{1} \mathrm{x}\left(\mathrm{Y}-\mathrm{y}_{1}\right)^{2}\right]+\left[\left(\mathrm{bd}^{3}\right) / 12+\mathrm{A}_{1} \mathrm{x}\left(\mathrm{Y}-\mathrm{y}_{1}\right)^{2}\right]$ $=8203.61 \mathrm{~mm}^{4}$

Now find out the maximum shear stress

$\mathrm{S}_{\mathrm{ys} 1}=$ Shear stress at junction of hub \& Flange

$\mathrm{S}_{\mathrm{ys} 1}=\mathrm{FAY}_{1} / \mathrm{IB}$

$$
=391.55 \mathrm{Mpa}
$$

$$
\text { Now } \begin{aligned}
\mathrm{S}_{\mathrm{ys} 2} & =\mathrm{B} / \mathrm{b} \times \mathrm{S}_{\mathrm{ys} 1} \\
& =3262.99 \mathrm{Mpa}
\end{aligned}
$$

Maximum Shear Stress

$\mathrm{S}_{\mathrm{ysmax}}=\mathrm{S}_{\mathrm{ys} 2}+\mathrm{S}_{\mathrm{ys} \text { add }}$

Here $S_{\mathrm{ys} \text { add }}=\left(\mathrm{F} \times \mathrm{A}_{\text {add }} \times \mathrm{Q}\right) /(\mathrm{I} \times \mathrm{b})$

Since $\mathrm{Q}=4.351 / 2$

$$
=2.177 \mathrm{~mm}
$$

Therefore $S_{\text {ys add }}=211.15 \mathrm{Mpa}$

Now find out the maximum Shear stress

$$
\begin{aligned}
\mathrm{S}_{\mathrm{ys} \max } & =\mathrm{I}_{\mathrm{m}}+\mathrm{S}_{\mathrm{ys} \text { add }} \\
& =3262.99+211.15 \\
& =3474.14 \mathrm{~N} / \mathrm{mm}^{2}
\end{aligned}
$$

Hence the design is safe, as the permissible shear stress is $\mathrm{S}_{\mathrm{ys}}=183 \mathrm{Mpa}$ and the induced stress is $3474.14 \mathrm{~Pa}$.

\section{E) Analysis of Beam}

First we have considered the cast iron material (Fe30) and two images are there one is for stress analysis and second is for displacement. Second we have considered the Steel material and there are two images one is for stress and another is for displacement.

Here we can see from analysis that the stresses are the same but the deflection is different. So we can say that the steel would be the better material for making the buffer.

Table 1: Comparison of Material

\begin{tabular}{|l|c|c|c|}
\hline SN & Material & Stress (Mpa) & $\begin{array}{c}\text { Displacement } \\
(\mathrm{mm})\end{array}$ \\
\hline 1 & Cast Iron & 4044.30 & 869.30 \\
\hline 2 & Steel & 4044.30 & 455.67 \\
\hline
\end{tabular}

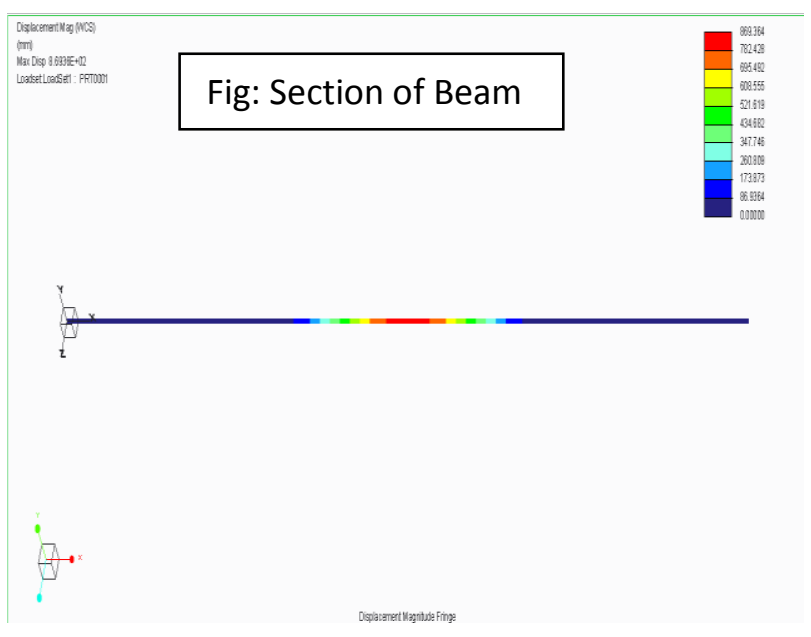

Fig 5: Displacement of Beam for Cast Iron 


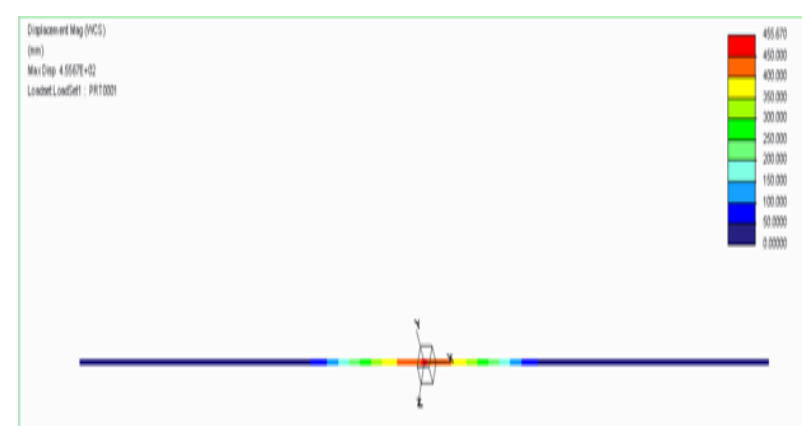

Fig 6: Displacement of Beam for Steel

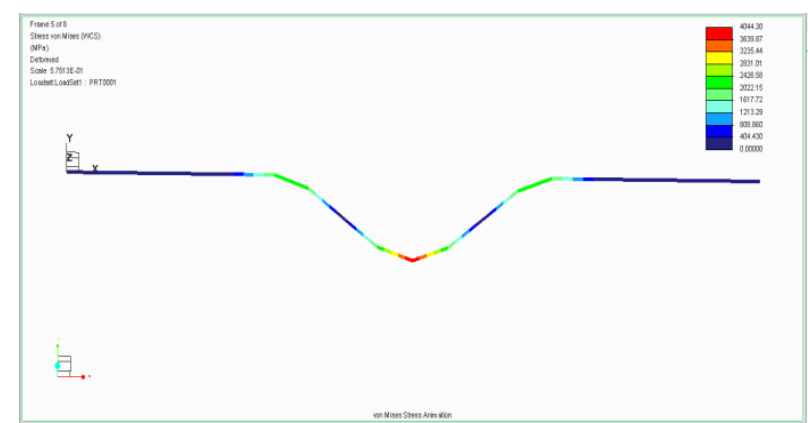

Fig 7: Stresses in Beam for Cast Iron

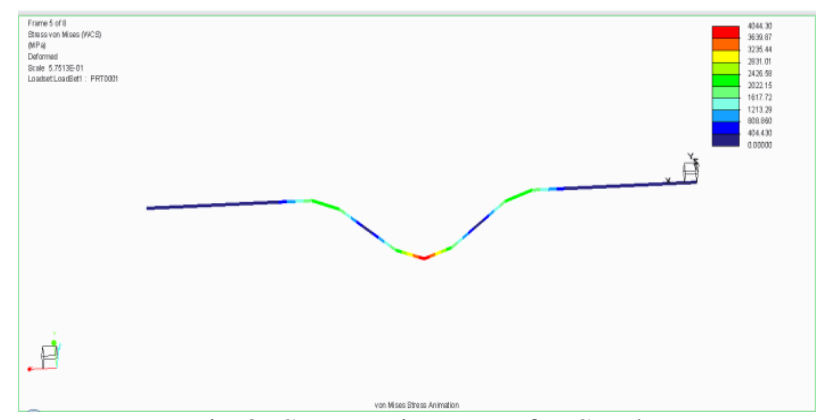

Fig 8: Stresses in Beam for Steel

F) Calculations for braking and bumper system

Assumption: Maximum force acting on bumper is assumed to be $90 \mathrm{~N}$.

Considering factor of safety as 1.25 , we design bumper for $90 \times 1.25=112.5 \mathrm{~N}$ force

Also, pressure used is $4 \mathrm{bar}=0.4 \mathrm{~N} / \mathrm{mm}^{2}$

1) For Applying Brakes:

For out-stroke $\mathrm{F}_{\mathrm{o} / \mathrm{s}}=\mathrm{P} \times \mathrm{A}$

$112.5=0.4 \times 0.7854 \mathrm{D}^{2}$

$\mathrm{D}^{2}=358.0978 \mathrm{~mm}^{2}$

So, $\mathrm{D}=18.92 \mathrm{~mm}$

Selecting standard value of $20 \mathrm{~mm}$ bore diameter, we calculate inner diameter.

Assuming In-stroke force to be equal to out-stroke force,

We assume in-stroke force to be $90 \mathrm{~N}$.

For factor of safety of 1.25 ,

In-stroke force is $90 \times 1.25=112.5 \mathrm{~N}$

For in-stroke,
Piston rod area $=\pi / 4 \mathrm{x} \mathrm{d}^{2}$

Effective area $=\pi / 4 \times\left(D^{2}-d^{2}\right)$

$=0.7854\left(202-\mathrm{d}^{2}\right) \mathrm{mm}^{2}$

So, $\mathrm{F}_{\mathrm{i} / \mathrm{s}}=0.4 \times 0.7854 \times\left(202-\mathrm{d}^{2}\right)$

$112.5=0.31416 \times\left(202-\mathrm{d}^{2}\right)$

On solving, we get $\mathrm{d}=6.47 \mathrm{~mm}$

Hence, selecting from standard values, inner diameter is $7 \mathrm{~mm}$. Keeping stroke of $50 \mathrm{~mm}$ for applying brakes, we get the cylinder dimensions as Cylinder bore $=20 \mathrm{~mm}$ Cylinder stroke $=50 \mathrm{~mm}$

Similarly, we calculate for Bumper.

2) For Bumper:

For out-stroke $\mathrm{F}_{\mathrm{o} / \mathrm{S}}=\mathrm{P} \times \mathrm{A}$

$112.5=0.4 \times 0.7854 \mathrm{D}^{2}$

$\mathrm{D}^{2}=358.0978 \mathrm{~mm}^{2}$

So, $\mathrm{D}=18.92 \mathrm{~mm}$

Selecting standard value of $20 \mathrm{~mm}$ bore diameter, we calculate inner diameter.

Assuming In-stroke force to be equal to outstroke force, we assume in stroke force to be $90 \mathrm{~N}$.

For factor of safety of 1.25 , in stroke force is $90 \times 1.25=112.5 \mathrm{~N}$.

For in-stroke,

Piston rod area $=\pi / 4 \mathrm{x} \mathrm{d}^{2}$

Effective area $=\pi / 4 \times\left(D^{2}-d^{2}\right)$

$=0.7854 \times\left(202-\mathrm{d}^{2}\right) \mathrm{mm}^{2}$

So, $F_{\mathrm{i} / \mathrm{s}}=0.4 \times 0.7854 \times\left(202-\mathrm{d}^{2}\right)$

$112.5=0.31416 \times\left(202-\mathrm{d}^{2}\right)$

On solving, we get $\mathrm{d}=6.47 \mathrm{~mm}$

Hence, selecting from standard values, inner diameter is $7 \mathrm{~mm}$. So, for both the double acting pneumatic cylinders bore diameter is $20 \mathrm{~mm}$. To increase the crashing distance in case of accidents, we increase the stroke length of cylinder used for extending the bumper. So, for bumper, cylinder stroke of $100 \mathrm{~mm}$ is suitable.

\section{IV- CONCLUSION}

The design of intelligent safety system is successful and prototype model is developed which fulfill the core objectives. Thus intelligent safety system is an automatic braking system which can be incorporated in a wide range of automobiles. This system can avoid vehicle accident by reducing collision rates. This system provides a glimpse into the future of automotive safety, and how much more advanced these individual systems can be for avoiding accidents and protecting vehicle occupants when they are integrated into one system. 


\section{REFERENCES}

[1] M. Rajyalakshmi, B. Kranthi Kumar, A. Krishna Vaibhav, Md Arief Khan, B. V. V. Siva Sai, "Design and Fabrication of Intelligent Mechatronic Braking System" International Journal of Science Technology \& Engineering, ISSN (Online): 2349-784X, Volume 4, Issue 10, April 2018

[2] Venkatesh Babu, R. Hariharan, "Fabrication of Sensor Operated Intelligent Braking System" International Journal of Pure and Applied Mathematics, ISSN: 13118080 (printed version); ISSN: 1314-3395 (on-line version), Volume 116, No. 14 2017, 307-313

[3] Kiran K. P, Shithin N.T, Ajay M. A, Akhilesh T.R, George Mathew, "Intelligent Braking System, Fabrication and Analysis of a Prototype" International Research Journal of Engineering and Technology, e-ISSN: 2395-0056, pISSN: 2395-0072, Volume 5, Issue 4, Apr-2018

[4] Abhay Bendekar, Abhijit Samanta, Arif Upletawala, Anup Chavan, "Intelligent Reverse Braking System by using Artificial Neutral Networks" International Journal of Engineering and Management Research, ISSN (Online): 2250-0758, ISSN (Print): 2394-6962, Volume-6, Issue-2, March-April 2016

[5] Tejsinh Pisal, Akshay Patil, Sanyukta Chaudhari, Utkarsha Khomane, Ashish Umbarkar, "Design and Development of Pneumatic Bumper with Automatic Braking System" International Conference on Ideas, Impact and Innovation in Mechanical Engineering (ICIIIME 2017), ISSN: 2321-8169, Volume 5, Issue 6, 211 $-218$

[6] S. Ruthara Kumar, K. Saravana Kumar, "Implementation of Intelligent Braking System (IBS) Using UART for Vehicle Control System" International Journal of Advanced Research Trends in Engineering and Technology, ISSN 2394-3777 (Print), ISSN 2394-3785 (Online), Vol. 3, Special Issue 1, March 2016

[7] Rajanikantha. M. A, Basavaraj. G. Kudamble, "Advanced Adaptive Cruise Control System for an Automobile" International Journal of Engineering and Management Research, ISSN (Online): 2250-0758, ISSN (Print): 23946962, Volume 5, Issue 4, August 2015

[8] Ashwin Francis, Abel Antoo, Jerald John, Augustin Sagar, Sreejith, "Intelligent Braking System for Automobiles" International Research Journal of Engineering and Technology, e-ISSN: 2395-0056, p-ISSN: 2395-0072, Volume 5, Issue: 03, Mar-2018

[9] Arun Chand, "A Case Study of Road Accidents in Kerala during 2010 to 2016" International Journal of Innovative Research in Science, Engineering and Technology, ISSN (Online) : 2319 - 8753, ISSN (Print) : 2347 - 6710, Volume 6, Special Issue 4, March 2017 